\title{
ТЕХНИЧЕСКОЕ ПЕРЕВООРУЖЕНИЕ КАК ОПРЕДЕЛЯЮЩИЙ ФАКТОР РАЗВИТИЯ ПРОИЗВОДСТВЕННОГО ПОТЕНЦИАЛА ОТДЕЛЬНЫХ ОТРАСЛЕЙ ${ }^{1}$
}

\author{
(C) 2021 г. Е. Н. Красина, Н. П. Горидько
}

Институт проблем управления РАН, г. Москва, Россия

Цель исследования - определение видов экономической деятельности, для которых модернизачия производства является одним из ключевых механизмов реализаџии его производственного потенциила.

Методология исследования. Авторами использованы общенаучные методы познания, а также анализ временных рядов, коррелячионный анализ.

Результат исследования. В результате выявлено, что динамика современного промышленного производства в России в XXI веке подвергалась серьезным колебаниям, причем мировой экономический кризис и дальнейшие макроэкономические шоки не позволили полностью реализовать потенциал во многих сферах производства. Зачастую причиной этого являются неудовлетворительные темпы обновления технической базы, которые не позволяют повысить производительность труда.

Перспективы исследования. $B$ статье предлагается ряд мероприятий, которые призваны частично решить существуюшие проблемы как в экономике в целом, так и в отдельных ее отраслях.

Ключевье слова: промышленное производство; основные фонды; техническое перевооружение; коэффициент обновления; коэффициент выбытия; производительность труда.

\section{TECHNICAL RE-EQUIPMENT \\ AS A KEY FACTOR OF THE PRODUCTION POTENTIAL ENHANCEMENT FOR SEPARATE BRANCHES OF ECONOMY}

\author{
(C) 2021 E. N. Krasina, N. P. Goridko
}

\section{Institute of Control Sciences, Russian Academy of Sciences, Moscow, Russia}

The aim of the study is to determine the types of economic activities for which the modernization of production is one of the key mechanisms for realizing its production potential.

Research methodology. The authors used general scientific methods of cognition, as well as analysis of time series, correlation analysis.

The result of the study. As a result, it was revealed that the dynamics of modern industrial production in Russia in the 21st century was subject to serious fluctuations, and the global economic crisis and further macroeconomic shocks did not allow full potential in many production areas. Often the reason for this is the unsatisfactory pace of updating the technical base, which does not allow increasing labor productivity.

Research prospects. Several measures that are designed to partially solve the existing problems both in the economy as a whole and in its some sectors are proposes in the paper.

1 Исследование выполнено при финансовой поддержке РФФИ в рамках научного проекта № 20-310-90008. 
Key words: industrial production; fixed access; technical re-equipment; renewal rate, retirement rate; labor productivity.

Введение. Сейчас во многих отраслях экономики наблюдается отставание производства от потребительского спроса, предъявляемого на современных рынках товаров и услуг, зачастую оно вызвано недостатком ресурсов на отечественных предприятиях и неготовностью имеющихся мощностей. Такого рода дефицит является не только барьером в развитии отдельных субъектов хозяйствования, но и сказывается на социально-экономическом положении страны в целом. Оценка производственного потенциала российских компаний за счет возможного преодоления недостатка ресурсов, в т.ч. путем модернизации собственного производства, внедрения более производительных или более экономичных технологий, позволит выработать управленческие решения по наращиванию выпуска конкурентной продукции, находящей своего покупателя не только на внутреннем, но и, возможно, на внешнем рынке.

\section{Анализ динамики промышленного} производства. На основании данных Федеральной службы государственной статистики для анализа динамики валового выпуска предприятий России в XXI веке построены гистограммы темпов роста производства по отдельным видам промышленного производства (рис. 1).

На рис. 1 в 2001 году заметен резкий спад изготовления транспортных средств (на 26,4\%). С 2002 по 2005 годы наблюдается значительный рост производства электронного оборудования, вычислительной техники, аппаратуры, средств измерений и испытаний (в общем на 33,2-43,2\%).

Отдельно следует отметить резкое сокращение выпуска продукции по всем видам экономической деятельности в кризисном 2009 году. В большей степени это касается сферы обработки древесины (снижение на $23,1 \%$ ), изготовления огнеупорных, изоляционных, звукопоглощающих (неметаллических) материалов, машин, технологических станков, транспортных средств, электронных и оптических приборов (уменьшение на 31,3-33,2\%). Скачок 2010 года по всем отраслям вызван, по нашему мнению, низкой базой сравнения, и выводы по возобновлению объемов производства необходимо производить на основании анализа стоимостных, а то и натуральных показателей.

Особое внимание с точки зрения оценки потенциала всех отраслей следует уделить развитию машиностроительного комплекса, поскольку именно его продукция (автоматизированная техника, компьютеры, оптическое и электронное оборудование, прессовочные и литейные машины, контрольноизмерительные приборы, металлорежущие инструменты и пр.) является базовой для современной российской промышленности и определяет технологический уровень страны, а также обеспечивает её безопасность [2]. Мировой кризис и последовавшее после него введение санкций заметно повлияли на отечественное станкостроение - в 20082009 годах и в 2013-2015 годах отмечается снижение производства (рис. 1). В 2016 году по сравнению с 2015 годом наблюдался рост на 5,5\% изготовления транспортных средств и на $6,9 \%$ - электрооборудования, на $14,9 \%$ — машин и техоборудования [5].

Оценка технологического перевооружения отдельных отраслей. В современных условиях научно-технического прогресса успешное развитие компаний напрямую зависит от обеспеченности обновленной техникой, способной создавать конкурентную продукцию инновационной направленности [3]. Техническую оснащенность предприятия в динамике можно оценить с помощью коэффициентов движения основного капитала обновления и выбытия основных фондов $\left(\mathrm{K}_{\text {обн }}\right.$ и $\left.\mathrm{K}_{\text {выб }}\right)$, изменение которых в XXI веке в России имеет четко выраженную тенденцию (рис. 2).

Из графика на рис. 2 можно сделать вывод, что в сглаженном виде наблюдается скорее линейная положительная динамика $\mathrm{K}_{\text {обн, }}$, и это свидетельствует о постепенном введении в производственные процессы нового и модернизированного оборудования. В 2010 

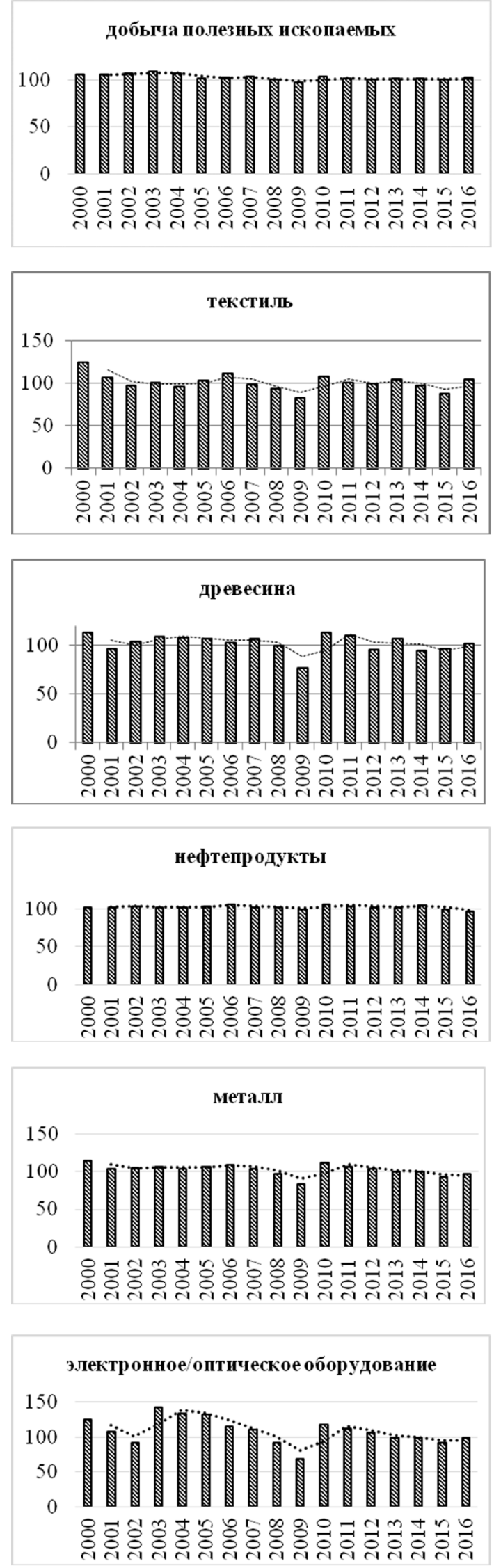
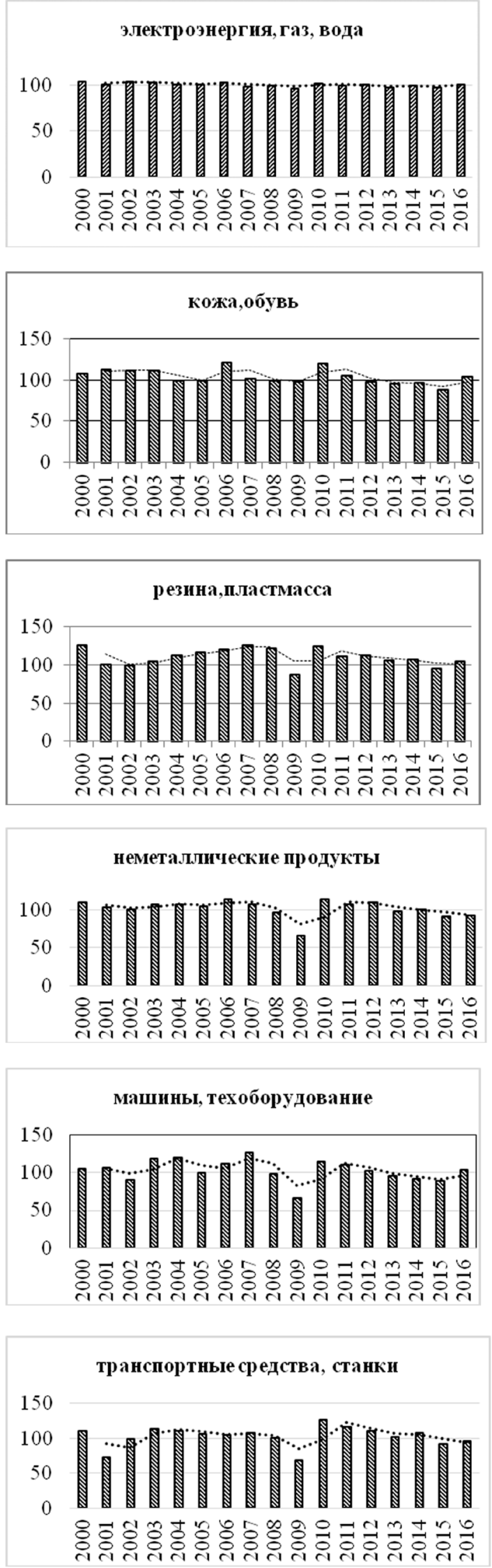

Рис. 1. Динамика промышленного производства (\% к предшествующему периоду), 2000-2016 гг. (построено авторами на основании [5]) 
и в 2015 годах заметны выбросы: снижение коэффициента обновления $\left(\mathrm{K}_{\text {обн } 2010}=3,7\right.$; $\left.\mathrm{K}_{\text {обн2015 }}=3,9\right)$ и резкое увеличение коэффициента выбытия (ликвидации) $\left(\mathrm{K}_{\text {виб2015 }}=1\right)$. По статистическим данным, в 2015 году отмечается также спад валового выпуска по большинству отраслей, резкое сокращение высокопроизводительных мест на 9,1\% (уменьшение на 1679,1 тыс. единиц) [5].

Коэффициент выбытия, превышающий единицу, может свидетельствовать об увеличении темпов списания негодных, изношенных непроизводительных станков в текущем году по сравнению с предыдущим. Рассматривая период с 2000 по 2009 годы, стоит отметить следующие значения этого показателя: $\mathrm{K}_{\text {выб́2000-2005 }}=1,1-1,3$ и $\mathrm{K}_{\text {выб2006-2009 }}=1$, которые могут указывать на то, что, несмотря на рост закупаемого оборудования, процент износа превышает темпы его обновления. С 2010 по 2019 годы значение показателя иное: $\mathrm{K}_{\text {выб2010-2014, 2016-2019 }}=0,7-0,8$, и это говорит о росте модернизации производства путем обновления основных средств.

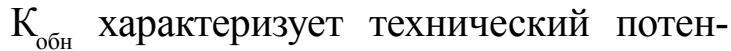
циал компании, приобретение современных спецстанков и введение их в эксплуатацию, что, как правило, отражается на улучшении качества выпускаемой продукции, увеличении производительности труда, расширяет возможности развития новаторства.

Анализ данного показателя по отдельным отраслям в динамике показал, что самые высокие его значения в 2019 году наблюдались в сфере добычи полезных ископаемых $\left(\mathrm{K}_{\text {обн }}(\mathrm{B})_{2019}=8,1\right)$, строительства $\left(\mathrm{K}_{\text {обн }}(\mathrm{F})_{2019}=9,9\right)$, финансовой деятельности $\left(\mathrm{K}_{\text {обн }}(\mathrm{J})_{2019}=13,9\right)$. Самый низкий коэффициент обновления - в здравоохранении, госуправлении и социальной сфере, образовании, операционной деятельности с недвижимостью $\left(\mathrm{K}_{\text {обн }}(\mathrm{K} \ldots \mathrm{N})_{2017-2019}=1,6-3,2\right)$, т.е. в этот перечень, как правило, попадают именно бюджетные организации (таблица 1). Последний факт наводит на мысль, что на сегодняшний день эти учреждения ограничены в средствах и основную часть средств, скорее всего, направляют на заработную плату сотрудников, а не на обновление материальных ценностей, в т.ч. основных фондов.

Темпы технического перевооружения на предприятиях напрямую зависят от величины инвестиций, вложенных в модернизацию производственной базы. Как правило, основной источник ассигнований - собственные средства (более $55 \%$ ), затем бюджетное финансирование (менее $19 \%$ ), остальная часть - заемные средства [4].

В обрабатывающих производствах в период с 2008 по 2019 годы наблюдается небольшое снижение коэффициента обновления, причем в посткризисные 2010 и 2016 годы падение максимальное; в 2008, 2013 и 2014 годах показатель по отрасли имеет самые высокие значения $\left(\mathrm{K}_{\text {обн }}(\mathrm{D})_{2008,2013,2014}=6,9\right)$ [5], что свидетельствует о более активном введении в эксплуатацию новых машин и оборудования. Изменение коэффициента обновления

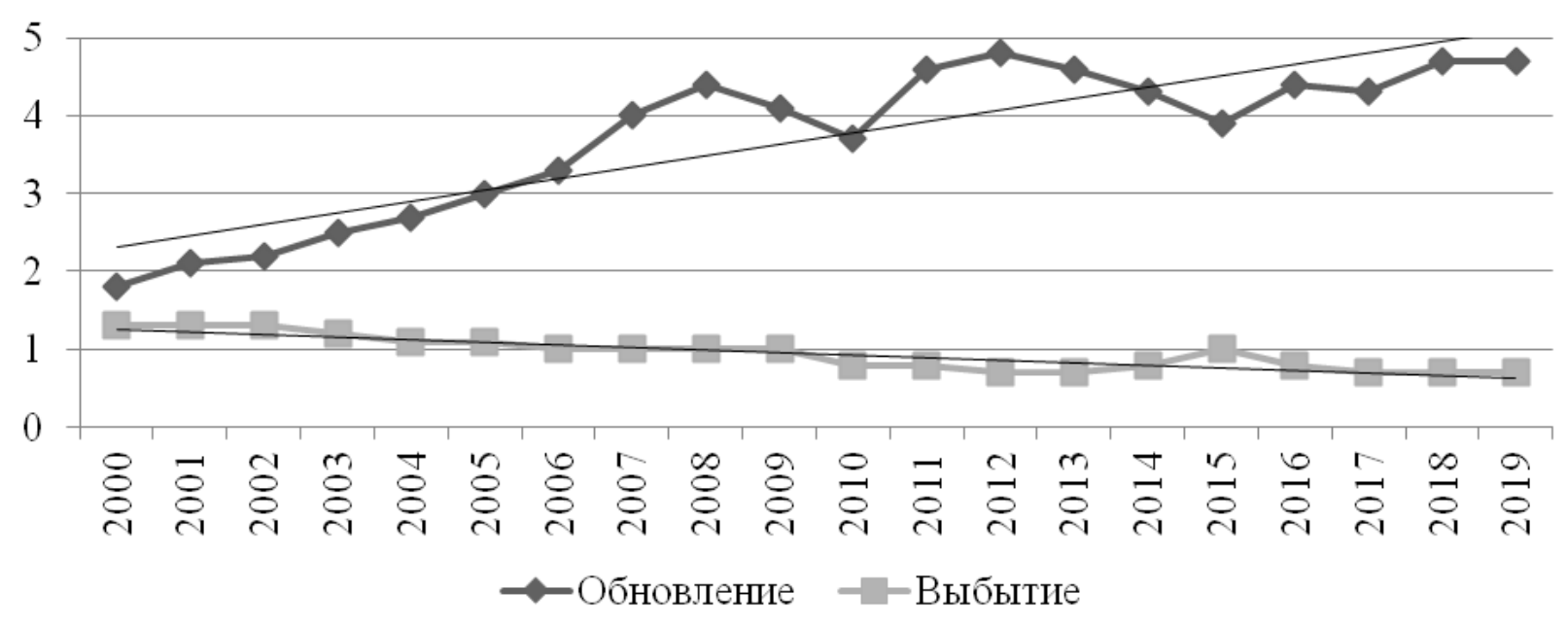

Рис. 2. Динамика коэффициентов обновления и выбытия основных фондов (\% к предшествующему периоду), 2000-2019 гг. (построено авторами на основании [5]) 
舀

فํ.

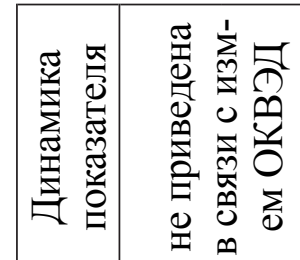

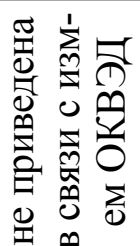

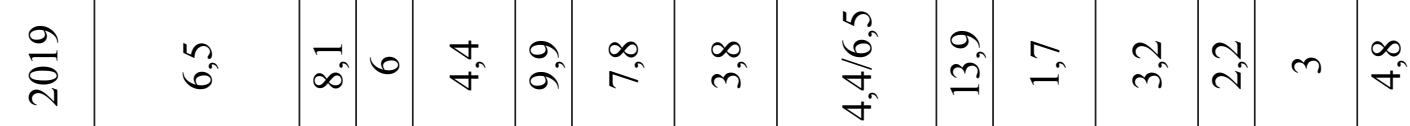

\begin{tabular}{|c|c|c|c|c|c|c|c|c|c|c|c|c|c|}
\hline$\stackrel{\infty}{\stackrel{\infty}{\sigma}}$ & $r$ & $\begin{array}{l}\infty \\
\infty \\
\infty\end{array}$ & $\hat{n}^{\circ}$ & $\begin{array}{l}6 \\
\Leftrightarrow\end{array}$ & $\exists$ & $\mathbb{\infty}_{\infty}^{\infty}$ & $\stackrel{\nabla_{+}}{+}$ & $\begin{array}{l}\hat{n} \\
\hat{\imath} \\
\dot{v}\end{array}$ & \pm & $\stackrel{0}{=}$ & $\hat{i}$ & $\overrightarrow{\mathrm{N}}$ & $\vec{m}$ \\
\hline
\end{tabular}

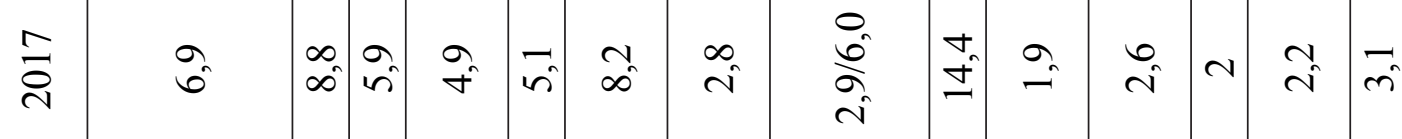

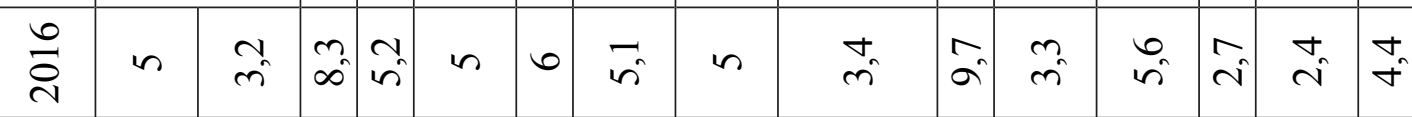

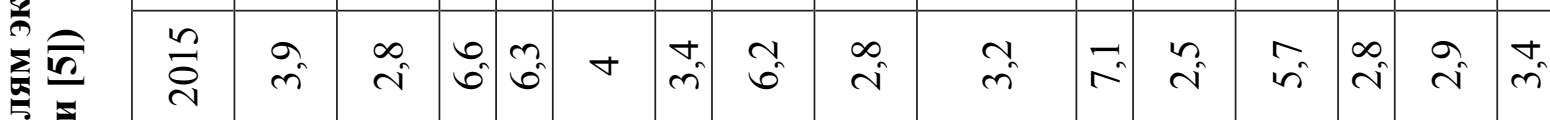

\begin{tabular}{|c|c|c|c|c|c|c|c|c|c|c|c|c|c|c|}
\hline$\stackrel{\Xi}{\Xi}$ & $\forall$ & $\sigma_{0}$ & $\infty$ & a & $=$ & $\infty$ & $n$ & $n$ & $\nabla$ & 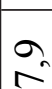 & 6 & 1 & $m$ & $\infty$ \\
\hline
\end{tabular}

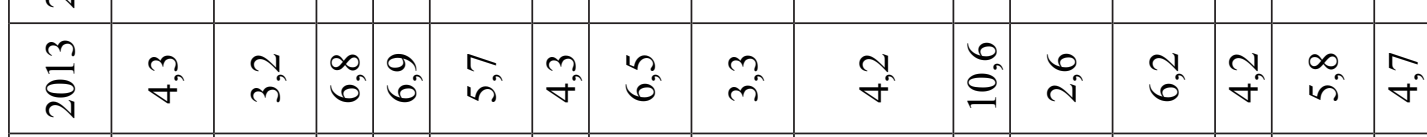

\begin{tabular}{|c|c|c|c|c|c|c|c|c|c|c|c|c|c|c|c|}
\hline 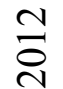 & $\stackrel{\sim}{\forall}$ & $\stackrel{\sim}{m}$ & ఫ̋ & $z^{n}$ & $\hat{n}$ & $\stackrel{n}{*}$ & $\begin{array}{l}0 \\
6\end{array}$ & $\stackrel{\nabla_{n}}{m}$ & $\vec{n}$ & $=$ & $\stackrel{\nabla}{\sim}$ & $\tilde{n}^{n}$ & $\stackrel{\sim}{*}$ & $\overline{6}$ & $\begin{array}{l}0 \\
\gamma^{\circ}\end{array}$ \\
\hline
\end{tabular}

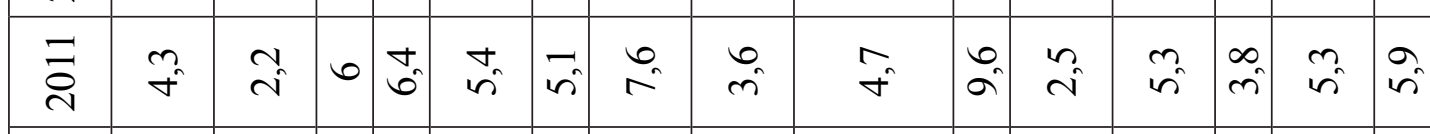

\begin{tabular}{|c|c|c|c|c|c|c|c|c|c|c|c|c|c|c|}
\hline$\stackrel{\circ}{\stackrel{0}{0}}$ & $\hat{m}$ & $N$ & $\vec{\nabla}$ & $\hat{n}$ & $\vec{\nabla}$ & m. & $t_{\sigma}$ & $\hat{m}$ & $m$ & $\stackrel{\infty}{n}$ & $\stackrel{m}{i}$ & $n$ & $\underset{m}{\sigma_{n}}$ & $\begin{array}{l}0 \\
\dot{\sigma}\end{array}$ \\
\hline
\end{tabular}

\begin{tabular}{|c|c|c|c|c|c|c|c|c|c|c|c|c|c|c|c|}
\hline \&े & F & 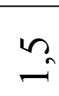 & $\widetilde{\Omega}$ & حֶ. & $\stackrel{0}{m}$ & $\underset{\dot{m}}{\nabla_{0}}$ & 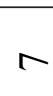 & $n$ & $\stackrel{\vec{m}}{m}$ & $\vec{r}$ & $\vec{a}$ & $\stackrel{0}{\sim}$ & r) & $\stackrel{g}{\forall}$ & gे \\
\hline
\end{tabular}

\begin{tabular}{|c|c|c|c|c|c|c|c|c|c|c|c|c|c|c|c|}
\hline$\stackrel{\infty}{\stackrel{8}{8}}$ & $\begin{array}{l}\infty \\
\forall\end{array}$ & $\stackrel{\infty}{\sim}$ & ठิे & $\hat{\sigma}$ & $\stackrel{\sigma_{n}}{m}$ & in & $\mathbb{\infty}_{\infty}^{\circ}$ & $\hat{m}$ & $\hat{m}$ & o. & $\stackrel{+}{i}$ & $\stackrel{\infty}{\sim}$ & $\stackrel{\sim}{\sim}$ & $\begin{array}{l}\infty \\
i\end{array}$ & $\begin{array}{l}n \\
n\end{array}$ \\
\hline
\end{tabular}

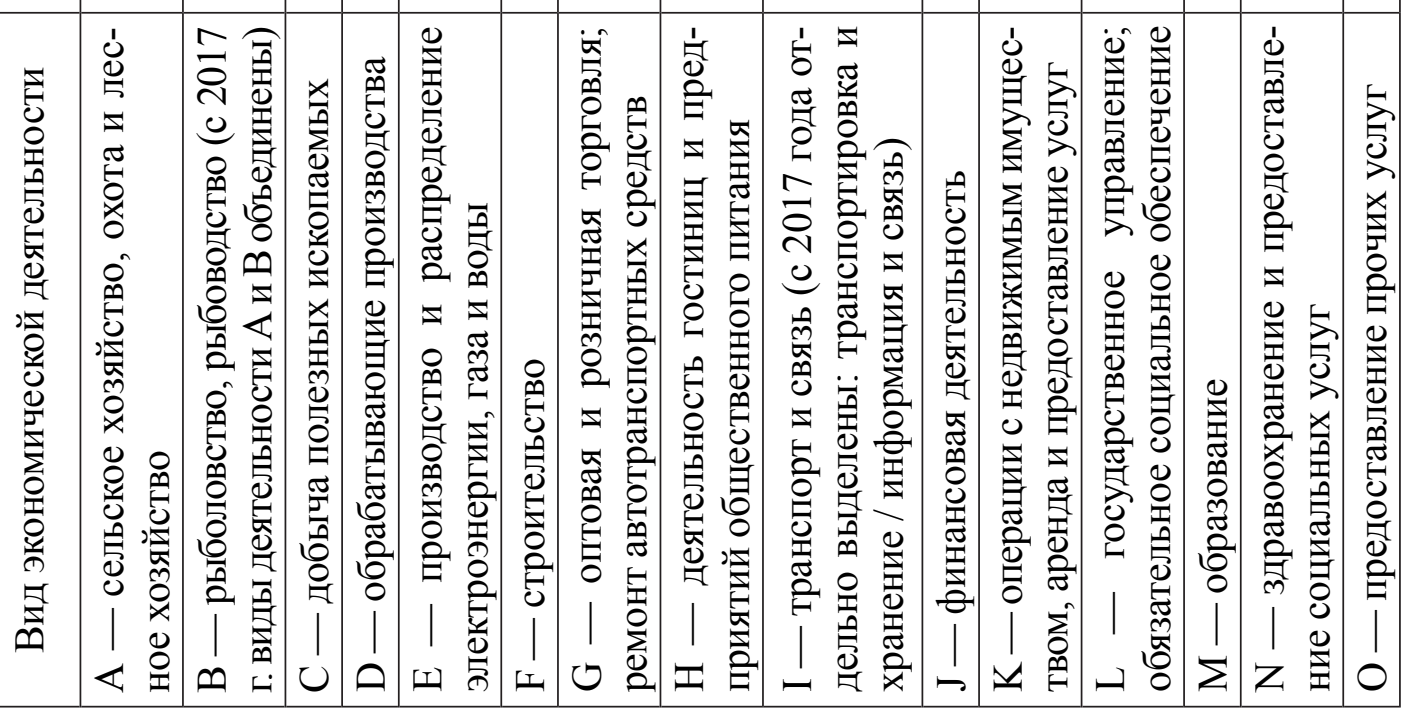


А (и В до 2017 г.) - Сельское хозяйство, охота, лесное хозяйство и рыболовство
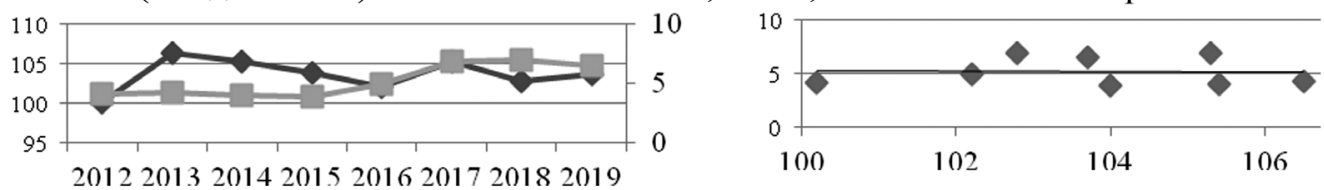

C - Добыча полезных ископаемых
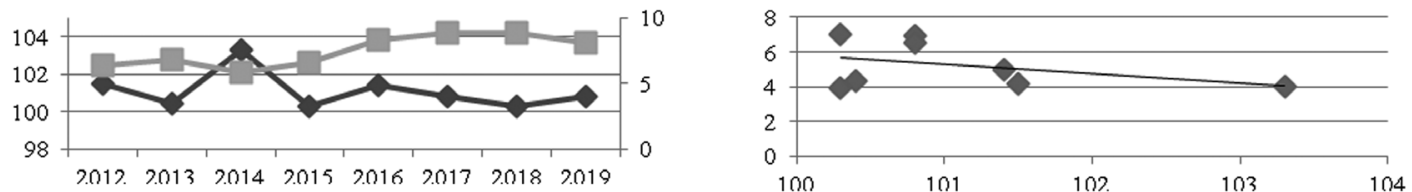

$\mathrm{D}$ - Обрабатывающие производства
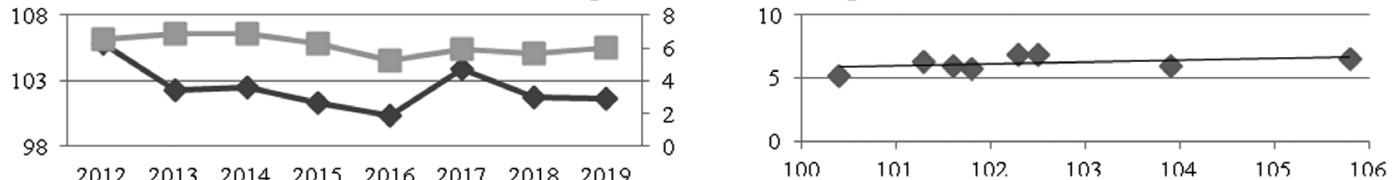

Е - Производство и распределение электроэнергии, газа и воды
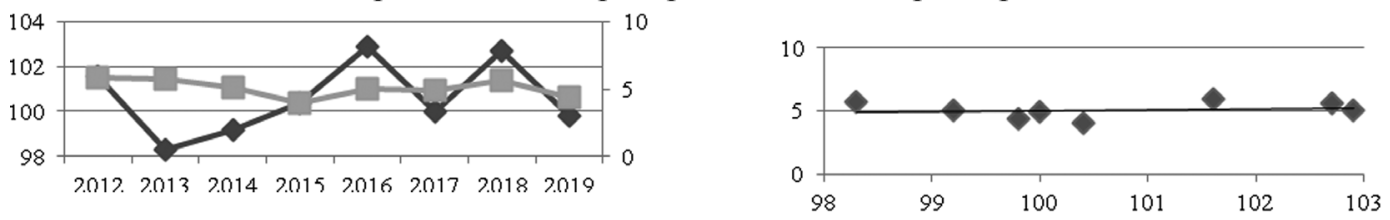

F - Строительство
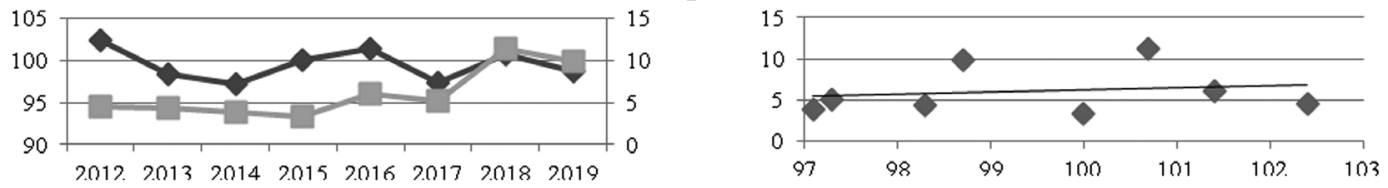

$\mathrm{G}$ - оптовая и розничная торговля; ремонт автотранспортных средств
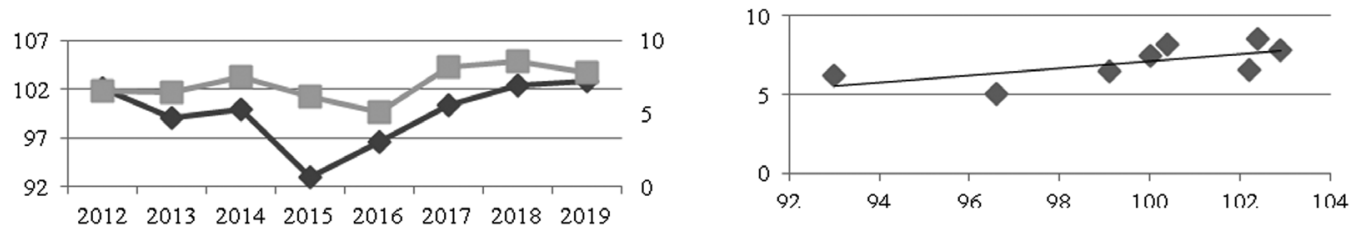

I - транспортировка и хранение
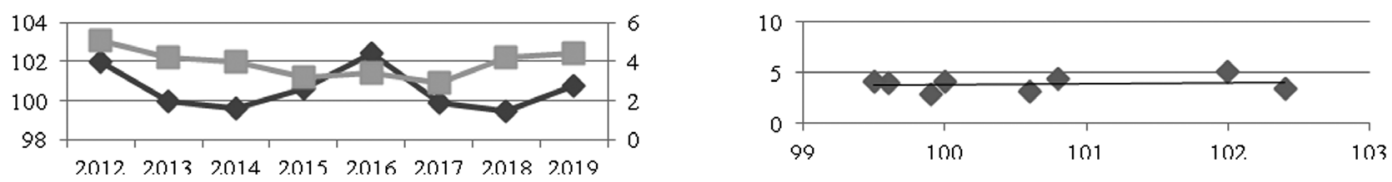

$\mathrm{K}$ - операции с недвижимым имуществом, аренда и предоставление услуг
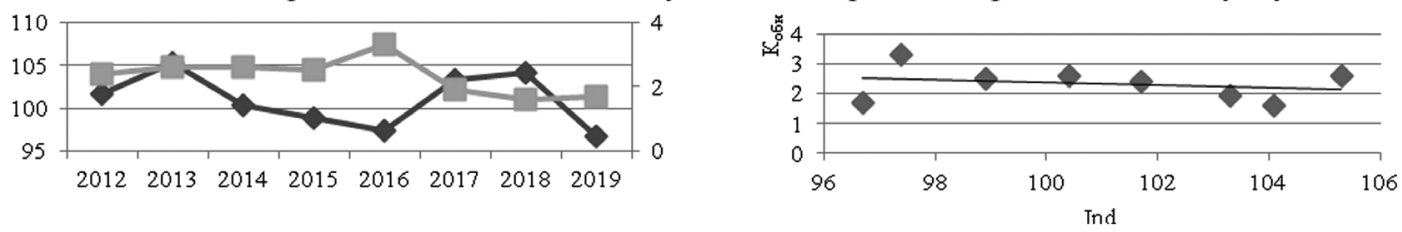

$\longrightarrow$ Ind (левая ось) $\quad-$ Кобн (правая ось)

Рис. 3. Связь производительности труда с обновлением технической базы, 2012-2019 гг. (построено авторами на основании [5]) 
мы исследуем наряду с динамикой коэффициента выбытия основных фондов, $\mathrm{K}_{\text {выб }}$ (таблица 2). Впрочем, по нашему мнению, для изъятия из производства машин и оборудования необходимость их замены при техническом перевооружении является поводом лишь частично. Главная же причина списания и ликвидации производственного оборудования - износ (физический и/или моральный), также основанием для выбытия может служить обмен, продажа, порча и др.

Судя по данным таблицы 2, в 2019 году значительно сократился парк сельскохозяйственной техники $\mathrm{K}_{\text {выб2019 }}(\mathrm{A})=1,6$ и оснащенность основным капиталом в информационной сфере $\mathrm{K}_{\text {выб2019 }}(/ \mathrm{I})=2,3$. Коэффициент выбытия в торговле, операциях с недвижимостью, здравоохранении $\mathrm{K}_{\text {выб2019 }}(\mathrm{G}$, Л, Т) $=1,0$. Меньше всего списано оборудования для обеспечения электроэнергией, газом и транспортировки $\mathrm{K}_{\text {выб_2019 }}(\mathrm{E}, \mathrm{I} /)=0,3[5]$.

Исследование связи модернизации производства с производительностью труда. В том случае, когда предприятия той или иной сферы заинтересованы в повышении эффективности производственной деятельности, в том числе в улучшении показателей ресурсоотдачи, реконструкция, модернизация и обновление основных фондов неизбежны [6]. Рост производительности труда путем автоматизации процессов производства, внедрения более продуктивного оборудования по большинству отраслей обеспечивает снижение трудоемкости, минимизацию брака, содействует повышению результирующих показателей, влияющих на конкурентоспособность.

Для выявления связи между изменениями производительности труда по некоторым видам экономической деятельности (Ind) и соответствующими коэффициентами обновления основных фондов $\left(\mathrm{K}_{\text {обн }}\right)$ построены графики на рис. 3.

Из графиков видно, что не во всех сфеpax деятельности исследуемые показатели тесно связаны. Так, например, по виду экономической деятельности « $\mathrm{G}$ - оптовая и розничная торговля; ремонт автотранспортных средств» с 2015 года наблюдается рост обеих величин, что может говорить о происшедшем в последний период технологическом сдвиге в отрасли, когда активное обновление основных фондов и параллельное внедрение организационных и маркетинговых инноваций привело к росту производительности труда.

Индекс производительности труда явно обратно пропорционален коэффициенту обновления основных фондов по виду деятельности «С - добыча полезных ископаемых», скорее всего, для этой сферы характерна технологическая ловушка, когда инвестиции направляются в заведомо устаревшие технологии [1] и не приносят ожидаемой отдачи.

В большинстве отраслей наблюдается очень слабая связь производительности труда с обновлением технической базы. Для сельского хозяйства и строительства заметна высокая дисперсия изменения показателей.

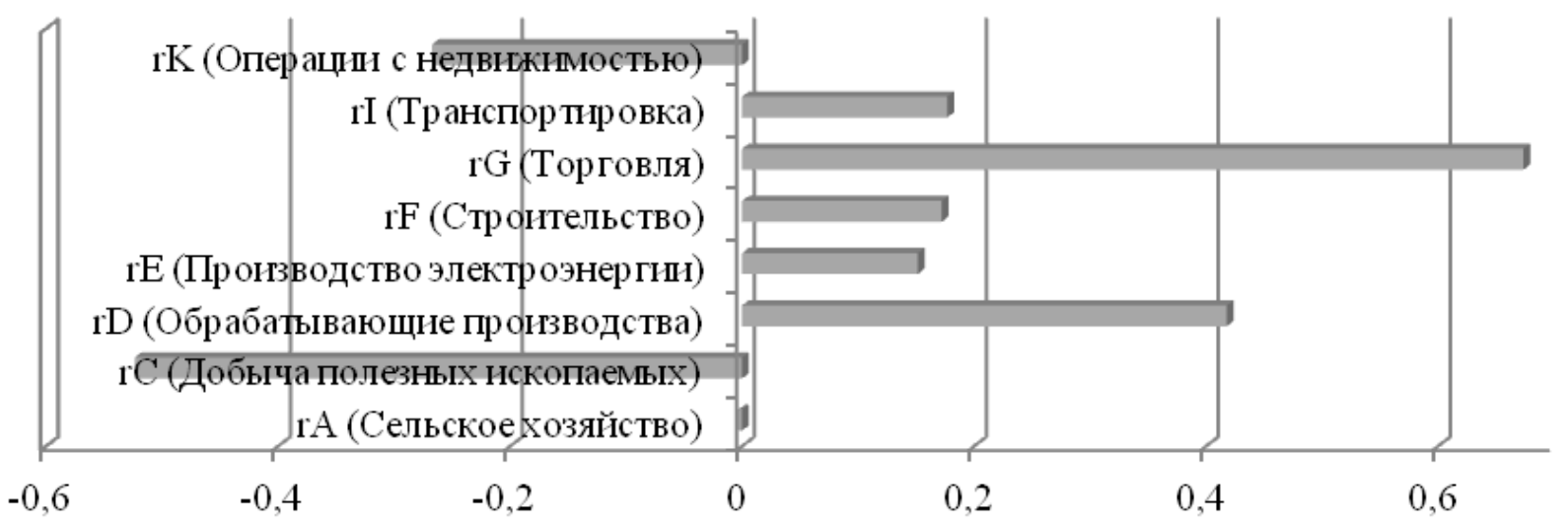

Рис. 4. Корреляционная связь производительности труда и обновления основных фондов в разрезе видов экономической деятельности, 2012-2019 гг.

(рассчитано авторами на основании [5]) 
Наши предположения о связи индекса производительности труда и коэффициента обновления основных фондов подтверждаются рассчитанными значениями коэффициента корреляции (рис. 4). Так, для вида экономической деятельности « $\mathrm{G}$ - оптовая и розничная торговля; ремонт автотранспортных средств» коэффициент корреляции самый высокий по модулю и положительный 0,67; для «С - добыча полезных ископаемых» он равен -0,52 и указывает на умеренную обратную связь.

Что же касается других рассматриваемых отраслей экономики, скорее всего, объемы обновления основных фондов и качество этого обновления не позволяют произвести таких изменений в производстве, которые бы отразились на повышении его эффективности. Кроме того, стоит учитывать и зависимость производительности труда от других факторов, так, например, в сельском хозяйстве на нее значительное влияние оказывают природные и климатические факторы, своеобразность ведения хозяйства.

Заключение. Проведенный анализ показал, что темпы технического перевооружения и модернизации основных фондов на сегодня являются неудовлетворительными с точки зрения повышения производительности труда, оптимизации использования имеющихся мощностей. Хотя положительная динамика обновления во многих видах экономической деятельности благоприятно сказывается на объемах производства, качественный скачок заметен только в сфере торговли, а добыча полезных ископаемых и вовсе характеризуется неэффективностью инвестиций. Основная проблема большинства отраслей - недостаток финансового обеспечения для модернизации производства — может быть решена путем разработки действенных механизмов привлечения и эффективного использования средств. Также по всем сферам деятельности необходимо обеспечить подготовку и переподготовку кадрового состава с учетом особенностей введения в эксплуатацию обновленной техники и высокотехнологичного оборудования. Кроме этого, имеет смысл разработка методики основания инвестиционной рентабельности проектов технического перевооружения.
В отношении отдельных видов экономической деятельности рекомендуется:

— в сфере торговли поддерживать темпы обновления основных фондов путем технологического перевооружения;

— в обрабатывающих производствах (базовой отрасли) предусмотреть использование механизма ГЧП для инвестиций в технологии более высокого уровня и произвести комплексную модернизацию производственной базы;

- увеличить инвестиции в развитие отечественного машиностроительного комплекса для уменьшения закупки импортного оборудования;

- разработать институциональные основы, позволяющие значительную часть прибыли добывающих компаний направлять на инновационную деятельность, связанную c разработкой технологий, повышающих производительность труда в отрасли;

- в сельском хозяйстве и операционной деятельности с недвижимостью улучшить организационно-регулировочный и управленческий механизмы обновления основных фондов.

\section{Литература}

1. Горидько Н.П., Нижегородиев Р.М. Технологическая ловушка или курс на новую индустриализацию: выбор для России // Российская экономическая модель: содержание и структура / Под общей ред. д.э.н., профессора В.И. Гайдука, д.э.н., профессора А.В. Бузгалина. - Краснодар: Просвещение-Юг, 2012. - С. 186-200.

2. Почукаева О.В., Орлова Т.Г. Российский рынок продукции станкостроения // Научные труды: Институт народнохозяйственного прогнозирования РАН. - 2013. T. 11. - C. 248-261.

3. Рутковская E.A. Динамика основного капитала по видам деятельности: оценка и анализ // Научные труды: Институт народнохозяйственного прогнозирования РАН. 2018. - T. 16. - C. 102-119.

4. Тугушева В.Р., Щербакова Л.В., Старостина К.И. Проблемы эффективного использования и воспроизводства основных фондов строительных предприятий современной России // Известия Пензенского госу- 
дарственного педагогического университета им. В.Г. Белинского. - 2006. — №2 (6). C. 54-58.

5. Федеральная служба государственной статистики [Электронный ресурс]. — Режим доступа: http://www.gks.ru/ (Дата обращения: 29.01.2021).

6. Goridko N., Krasina E. Investment in the Modernization and Reconstruction of Industrial Equipment: An Evaluation of Multiplier Effects in Russia // Stepnov I. (Ed.). / Technology and Business Strategy. - Springer International Publishing AG, 2021. - Pp. 179-194. - DOI: 10.1007/978-3-030-63974-7_13.

\section{References}

1. Gorid'ko N. P., Nizhegorodcev R.M. Tehnologicheskaja lovushka ili kurs na novuju industrializaciju: vybor dlja Rossii [Technological trap or a course for new industrialization: a choice for Russia] // Rossijskaja jekonomicheskaja model': soderzhanie i struktura [The Russian Economic Model: content and structure]/ In professor V.I. Gajduk, professor A. V. Buzgalin (eds.). - Krasnodar: Prosveshhenie-Jug, 2012. - Pp. 186-200.

2. Pochukaeva O. V., Orlova T. G. Rossijskij rynok produkcii stankostroenija [Russian market of machine tool construction products] // Nauchnye trudy: Institut narodnohozjajstvennogo prognozirovanija RAN [Scientific Works: Institute of National Economic Forecasting of the Russian Academy of Sciences]. — 2013. Vol. 11. - Pp. 248-261.

3. Rutkovskaja E.A. Dinamika osnovnogo kapitala po vidam dejatel'nosti: ocenka i analiz [Dynamics of fixed capital by types of activities: assessment and analysis] // Nauchnye trudy: Institut narodnohozjajstvennogo prognozirovanija RAN [Proceedings of the Institute of economic forecasting of the Russian Academy of Sciences]. - 2018. - Vol. 16. - Pp. 102-119.

4. Tugusheva V.R., Shherbakova L. V., Starostina K.I. Problemy jeffektivnogo ispol'zovanija i vosproizvodstva osnovnyh fondov stroitel'nyh predprijatij sovremennoj Rossii [Problems of efficient use and reproduction of fixed assets of construction companies in modern Russia] // Izvestija Penzenskogo gosudarstvennogo pedagogicheskogo universiteta im. V.G. Belinskogo [Proceedings of the Penza State Pedagogical University named after V.G. Belinsky]. — 2006. — №2 (6). Pp. 54-58.

5. Federal'naja sluzhba gosudarstvennoj statistiki [Federal State Statistics Service] [Jelektronnyj resurs]. — URL: http://www.gks.ru/ (Date accessed: 29.01.2021).

6. Goridko N., Krasina E. Investment in the Modernization and Reconstruction of Industrial Equipment: An Evaluation of Multiplier Effects in Russia // Stepnov I. (Ed.). / Technology and Business Strategy. - Springer International Publishing AG, 2021. - Pp. 179-194. - DOI: 10.1007/978-3-030-63974-7_13. 


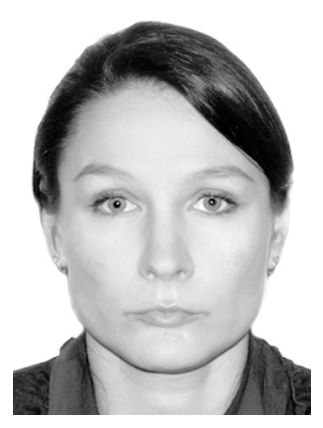

Красина Елена Николаевна - аспирант Института проблем управления РАН. Специалист в сфере проектного финансирования и бюджетирования, имеет стаж работы в российских наукоемких компаниях более 20 лет. Область научных интересов: инвестиции в основные фонды, обновление и модернизацию производства.

Krasina Elena Nickolaevna - Post-graduate Student, Institute of Control Sciences, Russian Academy of Sciences. Specialist in project finance and budgeting and more than 20 years works in the Russian knowledge-intensive companies. Scientific interests include the issues of investments in fixed assets, their renewal and modernization, as well as associated processes.

117997, г. Москва, ул. Профсоюзная, 65 65 Profsoyuznaya st., 117997, Moscow, Russia E-mail: elena_krasina@list.ru

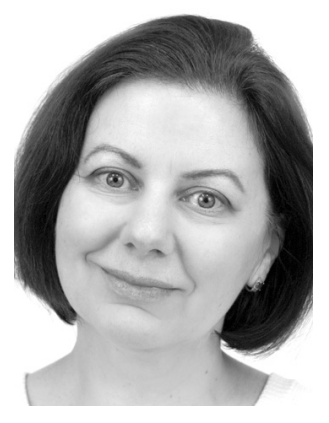

Горидько Нина Павловна - кандидат экономических наук, старший научный сотрудник лаборатории экономической динамики и управления инновациями Института проблем управления РАН. Автор более 200 научных работ, из которых 11 - монографии. Область научных интересов: моделирование и прогнозирование экономических процессов, управление инновациями, макроэкономическая динамика и макроэкономическое регулирование.

Goridko Nina Pavlovna - Candidate of Economic Sciences, Senior Researcher of the Laboratory of Economic Dynamics and Innovation Management, Institute of Control Sciences, Russian Academy of Sciences. Author of more than 200 scientific papers, 11 of which are monographs. Research fields are modelling and forecasting of economic processes, innovation management and macroeconomic dynamics and macroeconomic adjustment.

117997, г. Москва, ул. Профсоюзная, 65 65 Profsoyuznaya st., 117997, Moscow, Russia E-mail: horidko@mail.ru 